\title{
A Study on the Influence of Compatibilizer and Mica Filler on the Properties of Thermoplastic Polyurethane/Polyolefins Blends
}

\author{
MERLIN THOMAS*, ATUL D. KAMBLE ${ }^{\mathrm{a}}$ and NEETHA JOHN ${ }^{\mathrm{b}}$ \\ *Institute of Science and Technology for Applied Studies and Research (ISTAR), Vallabh \\ Vidyanagar, Gujarat -388120, India \\ ${ }^{a}$ Sophisticated Instrumentation Center for Applied Research and Testing (SICART), Vallabh \\ Vidyanagar, Gujarat- 388120, India \\ ${ }^{\mathrm{b}}$ Matha college of Technology, Ernakulum, Manakkppadi, N.Paravur, Kerala- 683511, India \\ mertho@yahoo.com
}

Received 2 July 2012 / Accepted 28 July 2012

\begin{abstract}
Improvement of mechanical and chemical properties can be achieved by melt blending of thermoplastic polyurethane (TPU) with polyolefins (PO's). Since TPU and PO's are completely immiscible polymers, property enhancement cannot be attained. Effect of incorporation of polypropylene copolymer (PPCP), TPU-g-MA, TPU-g-AA as compatibiliser on the miscibility of the blends and effect of mica filler to enhance the mechanical properties were studied. A single screw extruder was used to manufacture blends by melt mixing. The results of mechanical and morphological properties show that the blend of thermoplastic polyurethane (TPU)/PO's with suitable compatibiliser and mica gives excellent performance in all aspects.
\end{abstract}

Keywords: Polymer blend, Clay, Filler, Morphology, SEM

\section{Introduction}

It is well-known that blending is important not only for obtaining polymer materials with excellent properties, but for improving their processing capabilities and reducing the product costs. Owing to the needs of academic research and industrial application, most polymer materials are not homogeneous systems any longer, but multiphase complex systems obtained through blending ${ }^{1}$. Immiscible blends are thermodynamically unstable; the compatibiliser must be added to stabilize the morphology. This process of stabilizing polymer blends is commonly called compatibilisation ${ }^{2}$. The incorporation of particulate fillers into polymer matrices has been an extended technique to improve or modify some properties of neat polymers ${ }^{3}$. Solid minerals such as micas have a high surface energy, due to the presence of hydroxyl groups on the surface. Because of this feature, polar polymers such as polyurethane polyether could be thought of as being able to form $\mathrm{H}$-bonds with the 
hydroxyls available on the filler surface ${ }^{4}$. Kader et al. studied the effects of fillers on the mechanical, dynamic mechanical and aging properties of rubber-plastic binary and ternary blends derived from acrylic rubber, fluorocarbon rubber and multifunctional acrylates ${ }^{5}$. Nowadays, requirements for the production of new polymers with the best cost/performance balance are increasing; thus, research based on the study of polymer blends and polymer-filler composites is extensive ${ }^{6}$. Calcium carbonate $\left(\mathrm{CaCO}_{3}\right)$, clay, mica and $\mathrm{TiO}_{2}$ are the inorganic materials which are most widely used as filler in polymers ${ }^{7-11}$. The incorporation of calcium carbonate, clay, mica, $\mathrm{TiO}_{2}$ in thermoplastics is used to modify the mechanical properties and morphology of the polymers. This filler improves Young's Modulus, but it also decreases impact strength, toughness and elongation at break, it is generally accepted that compatibilisers serve as polymeric surfactants for immiscible blends by migration to the interface and thereby lowering the interfacial tension. Calcium carbonate and clay have been already established as successful fillers for improving the mechanical properties of thermoplastic polyurethane/polyolefins blends ${ }^{12,13}$.

In the present study attempts have been made to use particulate mica as filler for TPU/PO's blends with and without compatibiliser, with the objective to investigate the potential of this mica in bringing about improvements in mechanical, morphological and thermal on the properties of the final compound ${ }^{14}$.

\section{Experimental}

Low density polyethylene (LDPE), Grade: 24FS040, High Density Polyethylene (HDPE), Grade: MA60200, Polypropylene (PP), Grade: H110MA, supplied by Reliance India Ltd, Baroda. Thermoplastics polyurethane (TPU) with 85 shore A hardness, supplied by Bayer, India. Engage: polyolefin elastomer, grade 8402, supplied by DuPont Dow Elastomers, USA, ethylene vinyl acetate copolymer (EVA) and PPCP (Grade: MI 1530) supplied by Reliance India Ltd, Baroda, commercial mica filler.

\section{Blending process}

The thermoplastic polyurethane and polyolefins were preheated for three hours. The blends of TPU and polyolefins (PO) with and without compatibiliser were made using single screw extruder. Composition of the TPU/PO blends were 95/5, 90/10, 85/15, 80/20, 75/25 and $70 / 30$ and mixed with 20 parts of each mica filler on a two roll mill. These blends were grinded and used for making test specimen. Specimens for different mechanical testing were prepared using injection moulding machine.

\section{Analysis of mechanical properties}

The tensile strength and tensile modulus of all the blends were carried out at room temperature according to ASTM D-638. The flexural strength and flexural modulus of blends were done according to ASTM D-790. The Izod impact strength test of all blends was carried out at room temperature according to ASTM D-256. Shore D hardness of the blends was determined according to ASTM D-2240.

\section{Morphological properties}

The fracture surface of the blend samples were analyzed with a Philips, Scanning Electron Microscope (SEM). The surface morphology of the TPU/PO's blends with or without compatibiliser was examined in scanning electron microscope in the inert atmosphere of nitrogen gas. 


\section{Results and Discussion}

\section{Mechanical properties}

\section{Tensile properties}

Figure 1-3 show the variation of tensile strength as a function of mica in 20 parts into the TPU/PO's blends. The tensile strength of the TPU/PO's such as TPU/LDPE, TPU/HDPE, and TPU/PP blends increases with addition of mica and compatibiliser into the polymer blend matrix as compared to blends without mica and compatibiliser. Tensile strength of blends increases with increase polyolefins up to around 20\% and then drops.

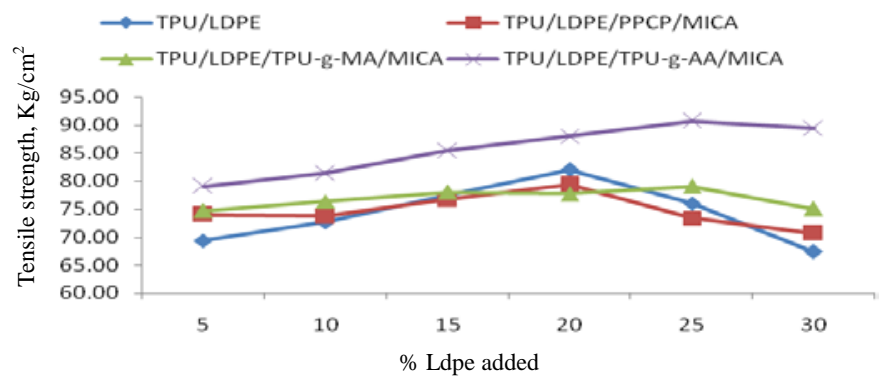

Figure 1. Tensile strength of TPU/LDPE with and without mica

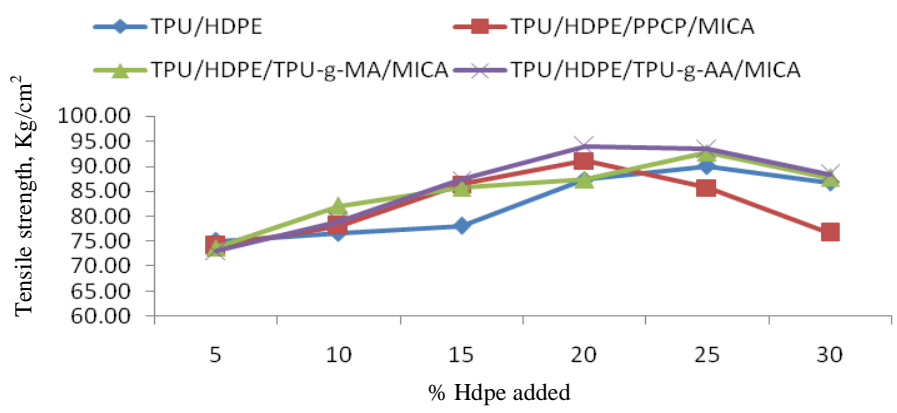

Figure 2. Tensile strength of TPU/HDPE with and without mica

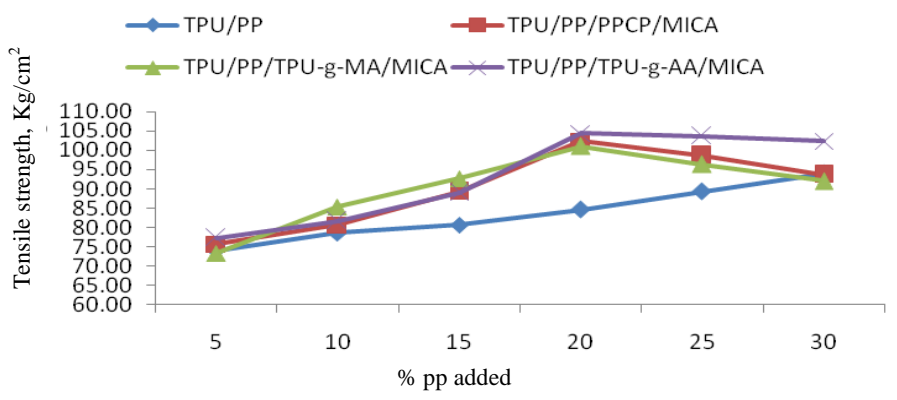

Figure 3. Tensile strength of TPU/PP with and without mica

Tensile modulus also increases with addition of the mica into polymer blends as shown in Figures 4-6. The increase in the amount of polyolefins into polymer blends increases the tensile modulus of blends containing mica. The increment ${ }^{15}$ may be due to the platy structure of the mica providing good reinforcement. Mica filler uniformly disperses into 
polymer blend matrix, mica particles make the crack propagation path longer, absorb a portion of the energy and enhance the polymer properties. Therefore, the surface fracture energy increases and the strength of the blends should also increase due to the presence of filler ${ }^{16}$.

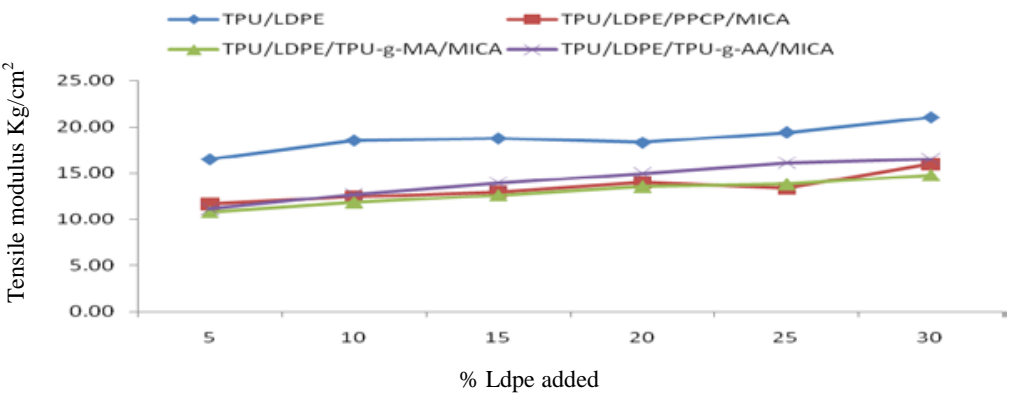

Figurre 4. Tensile modulus of TPU/LDPE blends with and without mica

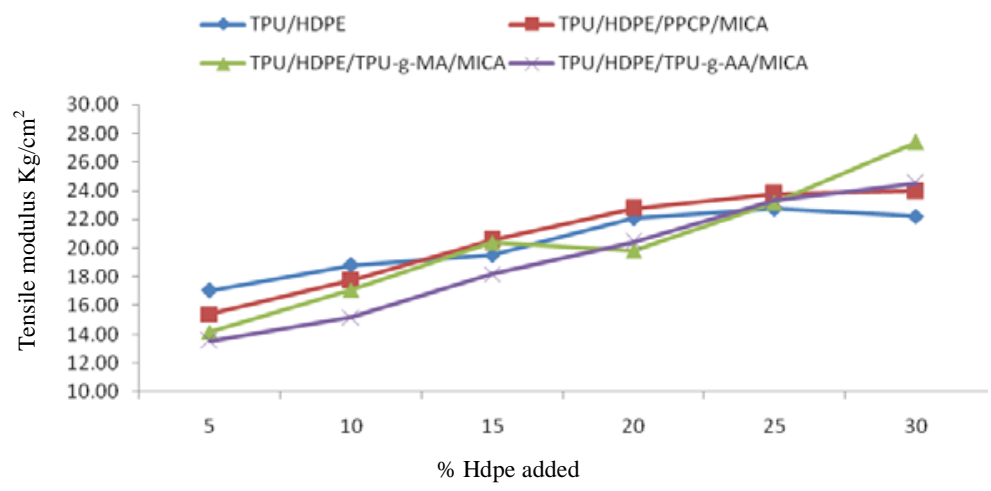

Figure 5. Tensile modulus of TPUH blends with and without mica

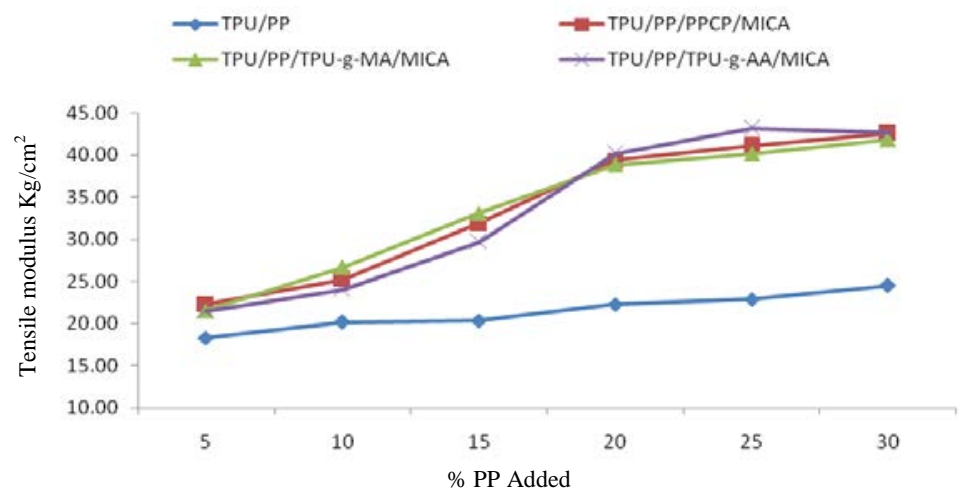

Figure 6. Tensile modulus of TPU/PP blends with and without mica

The effect of compatibiliser and mica filler on the elongation property of TPU/PO's blends is shown in the Figures 7-9. Elongation of the TPU/LDPE and TPU/HDPE shows improvement in the elongation after the addition of the mica filler indicating good dispersion of filler into the matrix. But reverse effect was observed in to the TPU/PP blend after the addition of mica into the blends matrix. An elongation of the TPU/PP blends decrease with 
addition of the mica may be due to interference is created through the physical interaction and immobilization of the polymer matrix by the presence of mechanical restraints. So as the filler concentration increases the elongation gets reduced ${ }^{17}$.

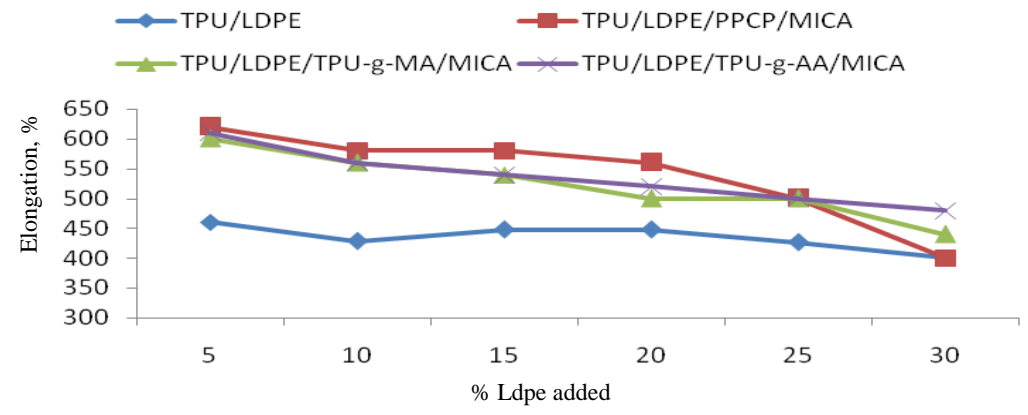

Figure 7. Effect of compatibiliser and clay filler on the elongation of TPU/LDPE blends

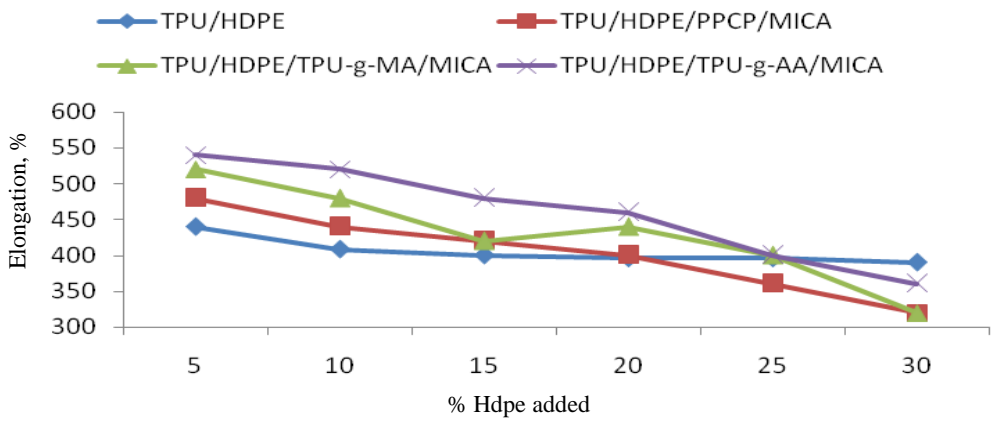

Figure 8. Effect of compatibiliser and clay filler on the elongation of TPU/HDPE blends

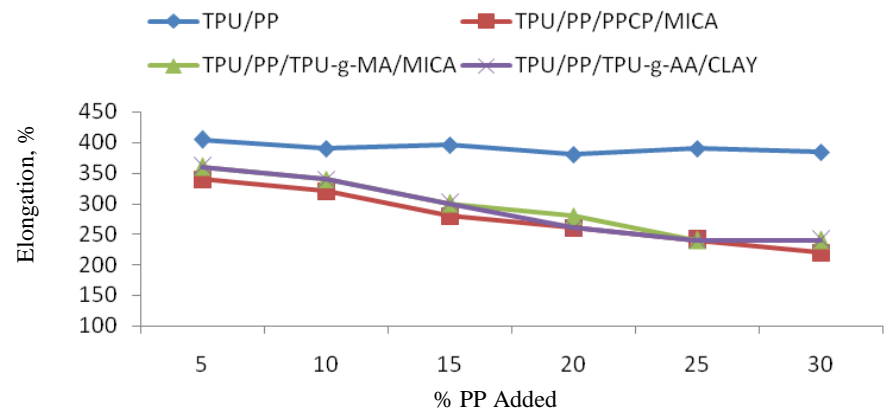

Figure 9. Effect of compatibiliser and clay filler on the elongation of TPU/PP blends

\section{Flexural properties}

Figures 10-12 show the variation in flexural strength of TPU/PO's blends with and without mica and compatibiliser. The flexural strength of blends with compatibiliser increases with addition of 20 parts of mica. There is also significant increase in the flexural strength with increasing concentration of polyolefins into blends with mica as shown in the Figure 4. Flexural strength of blends TPU/LDPE, TPU/HDPE and TPU/PP increase with addition of mica and it is due to good dispersion of filler into polymer blend matrix and hence increase in the total area for deformation stress. 


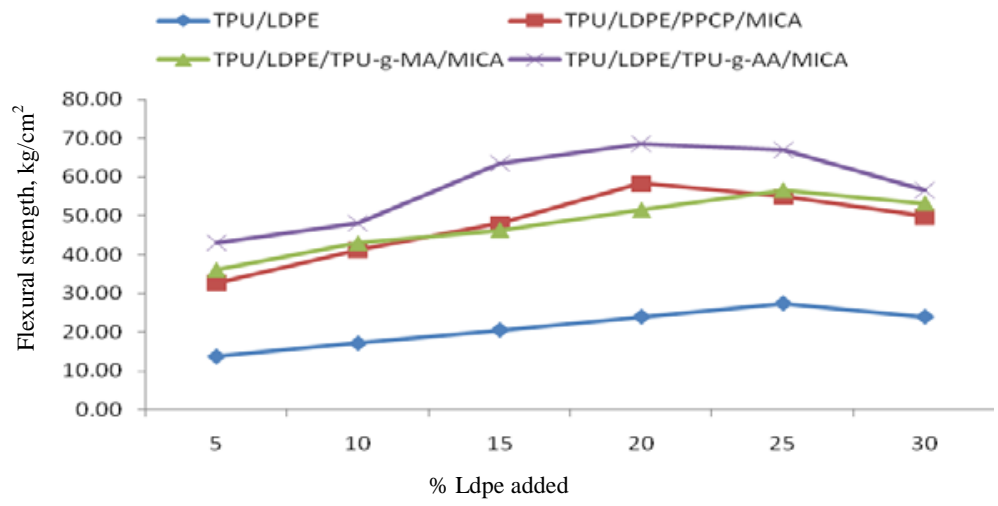

Figure 10. Flexural strength of TPU/LDPE with and without mica

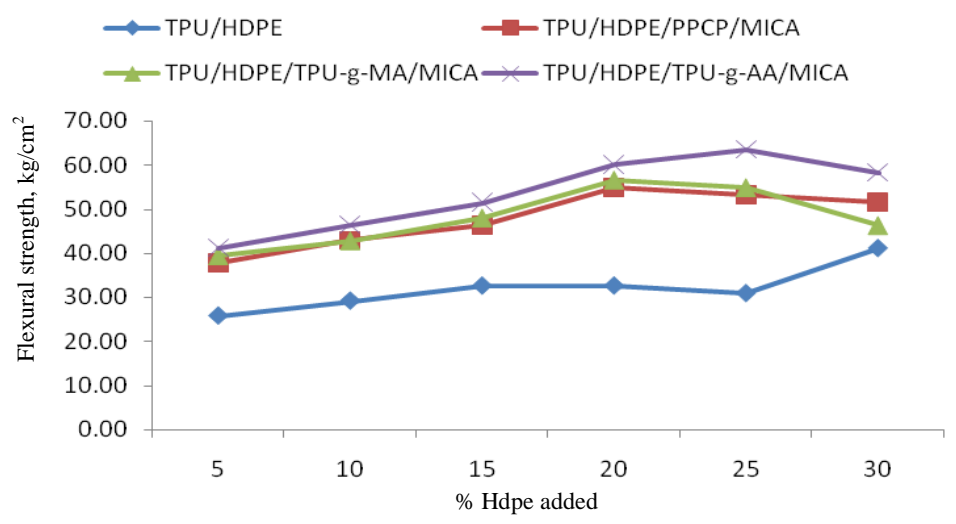

Figure 11. Flexural strength of TPU/HDPE with and without mica

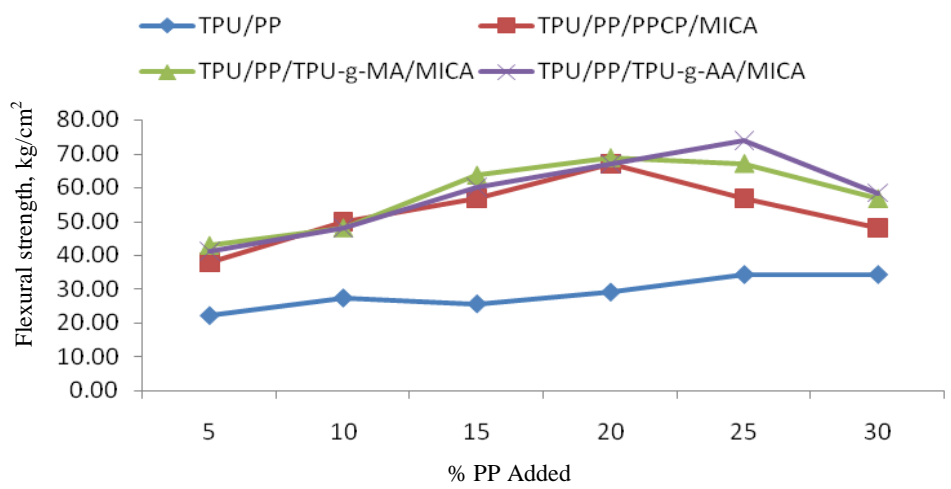

Figure 12. Flexural strength of TPU/PP with and without mica

Flexural modulus of TPU/LDPE, TPU/HDPE and TPU/PP blends with and without compatibiliser and mica are shown in Figures 13-15. In each of the TPU/PO's blends, flexural strength is found to be increased with addition of mica. Increase in the flexural modulus of TPU/HDPE, TPU/PP and TPU/LDPE blends with addition of mica may be due to good interaction between mica filler and blends matrix as compared to TPU/PO's without filler and compatibiliser. 


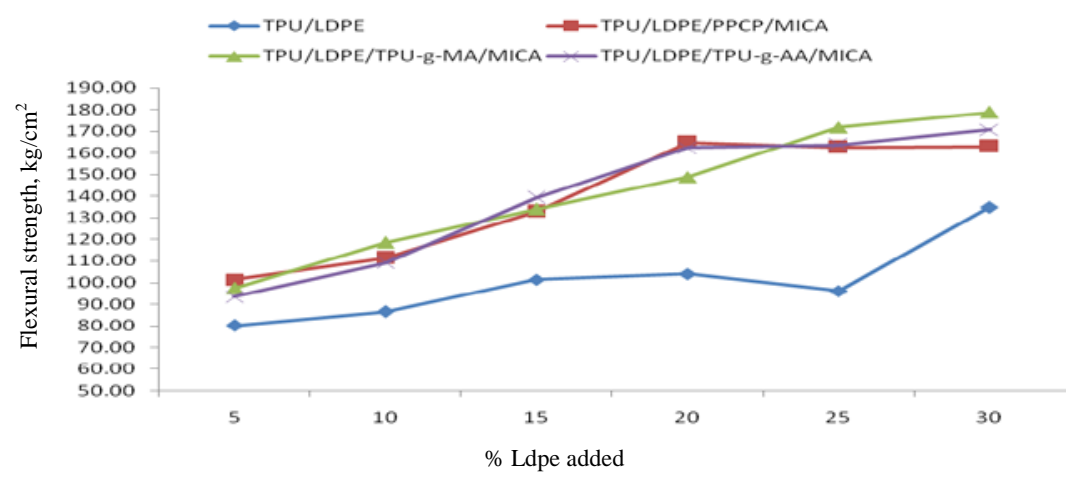

Figure 13. Flexural modulus of TPU/LDPE with and without mica

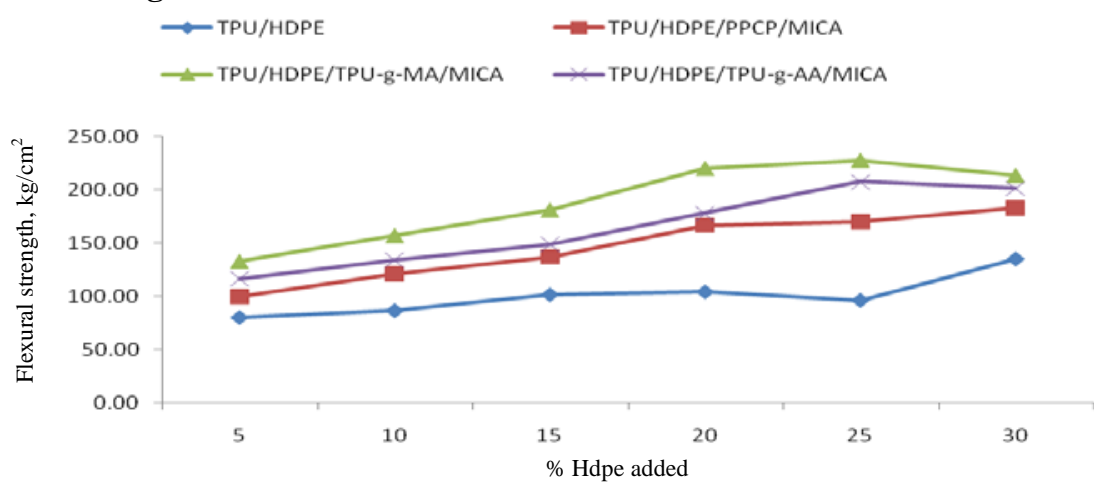

Figure 14. Flexural modulus of TPU/HDPE with and without mica

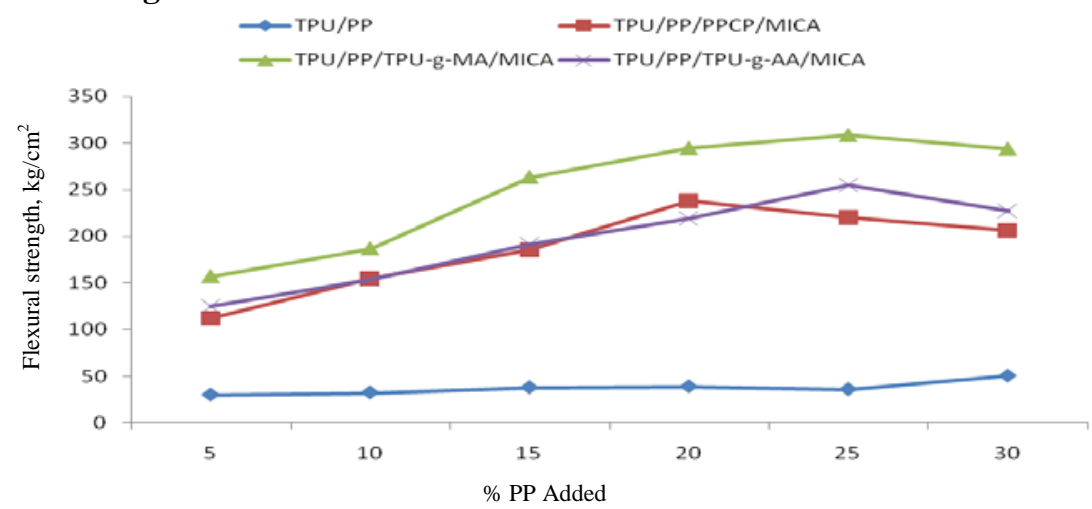

Figure 15. Flexural modulus of TPU/PP with and without mica

\section{Impact strength}

Figures 16-18 illustrate the variation of impact strength with mica loading on the TPU/PO's blends with and without compatibiliser. It is clear from these figures that there is a slight increase in impact strength with $5 \%$ of the polyolefins into the TPU matrix and then show a decreasing pattern with further addition of polyolefins. Decrease in impact strength may be due to the fact that particle size of the mica was not enough to block the crack propagation resulting in reduction of the impact strength. Another reason of decrease in impact strength 
may be due to reduction of elasticity ${ }^{15}$ of material due to filler addition and thereby reducing the deformability of matrix and in turn the ductility in the skin area, so that the composite tend to form a weak structure. An increase in concentration of filler reduces the ability of matrix to absorb energy and thereby reducing the toughness, and impact strength.

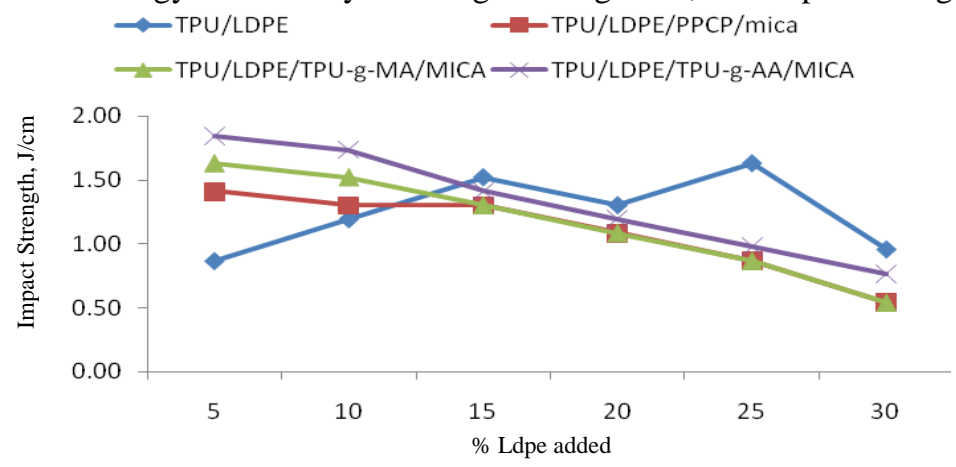

Figure 16. Impact strength of TPU/LDPE with and without mica

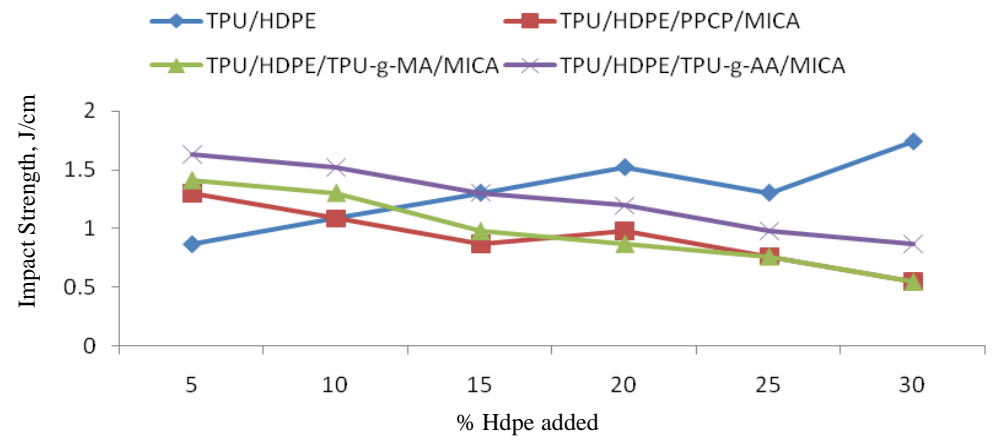

Figure 17. Impact strength of TPU/HDPE with and without mica

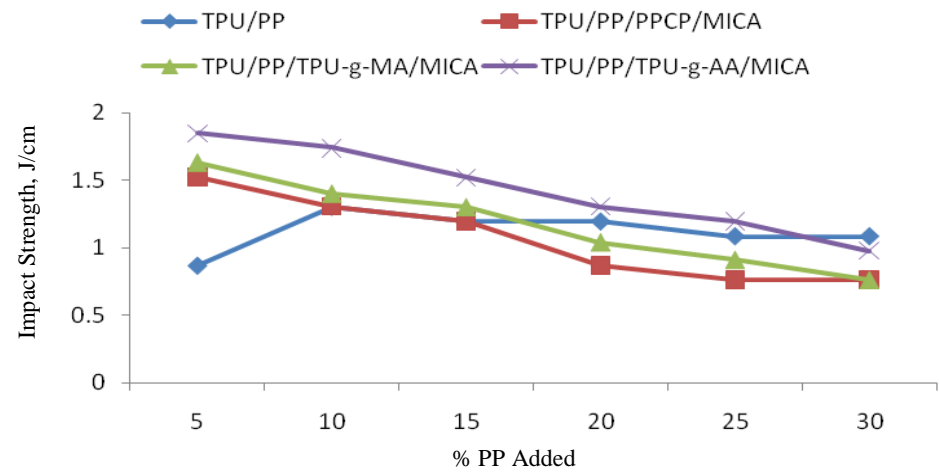

\section{Hardness}

Figure 18. Impact strength of TPU/PP with and without mica

Figures 19-21 show the variation in hardness of TPU/PO blends with and without compatibiliser and mica. Shore D hardness was found to be increased with addition of mica into the TPU/LDPE, TPU/HDPE and TPU/PP blend matrix. An increase in the hardness may be due to the improvement in the toughness of the polymer blends after addition of mica filler. 


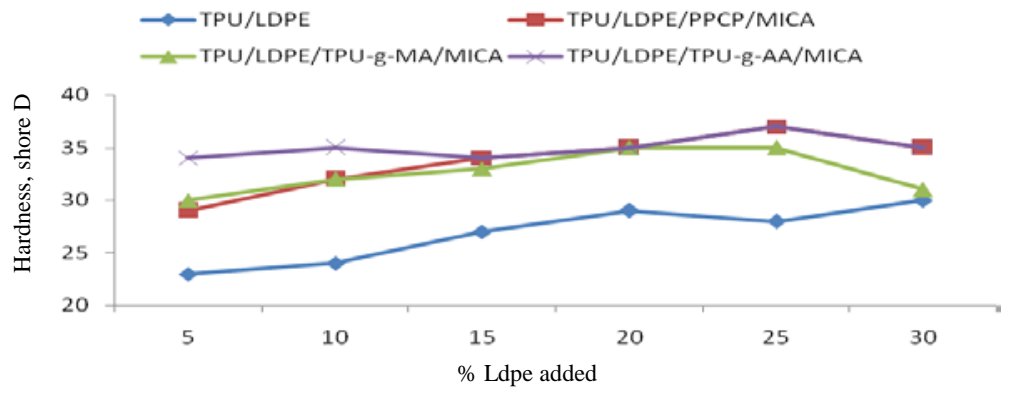

Figure 19. Hardness of TPU/LDPE with and without mica

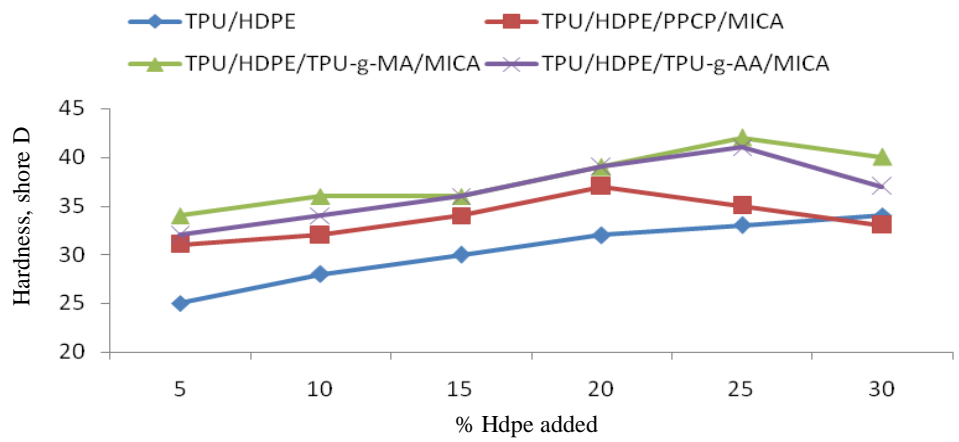

Figure 20. Hardness of TPU/HDPE with and without mica

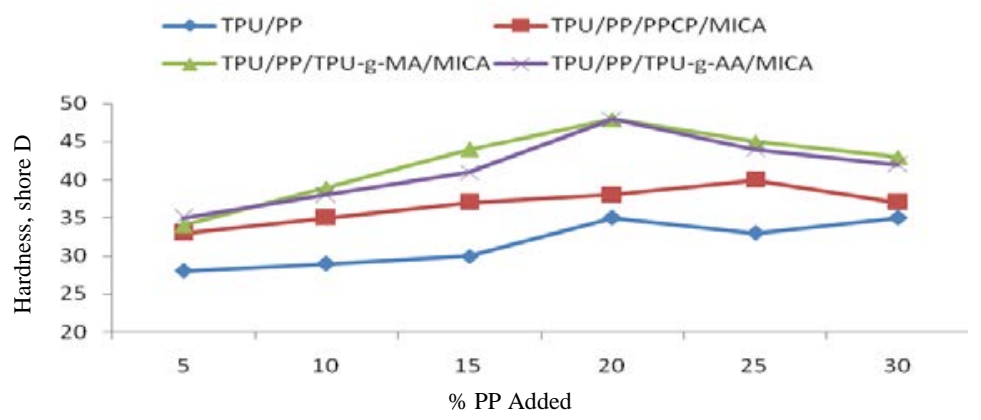

Figure 21. Hardness of TPU/PP with and without mica

\section{Morphological properties}

SEM is used to study the morphology of TPU/PO's blends with and without compatibiliser and mica. Figures 22-33 show the SEM images of TPU/PO's blends with 20 percentage concentration of mica. The interaction between the filler and the blends gets increases due to good dispersion of the filler particles into the blend matrix. The presence of cryogenic fracture along the boundaries of the blends without compatibiliser indicates the immiscibility of the two polymers blends in to the blends without compatibiliser. When compatibilisers and mica were added into the TPU/PO's blends, the blends display significantly finer morphology. The filler particles are sufficiently small to enable good distribution in the matrix. The clay particles are uniformly dispersed within the TPU/PO's blends matrix and no aggregation of filler particles are observed. 


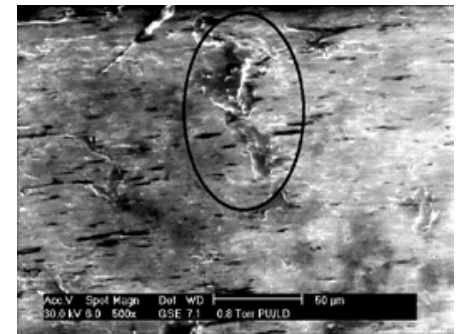

Figure 22. TPU/LDPE

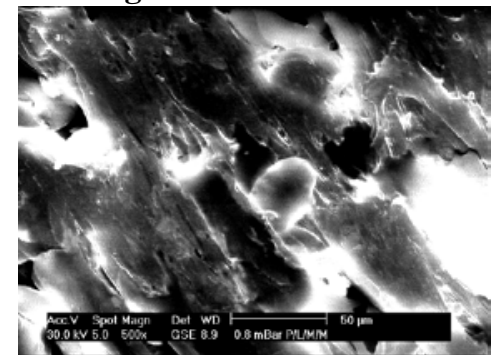

Figure 24. TPU/LDPE/TPU-g-MA/mica

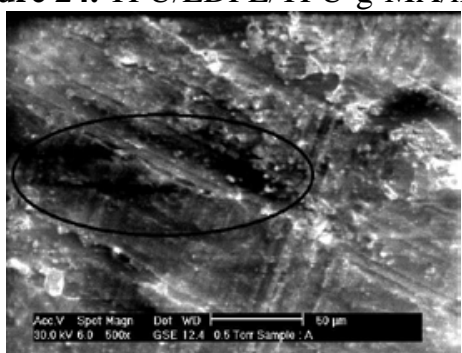

Figure 26. TPU/HDPE

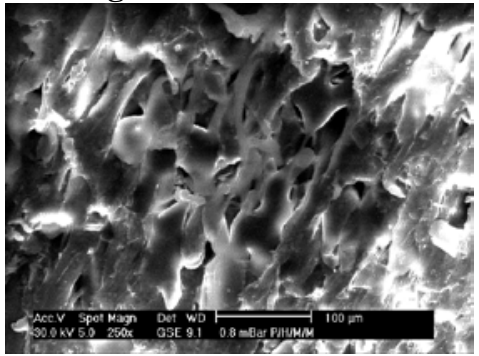

Figure 28. TPU/HDPE/TPU-g- MA/ mica

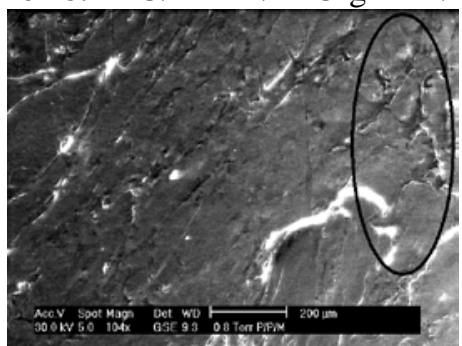

Figure 30. TPU/PP

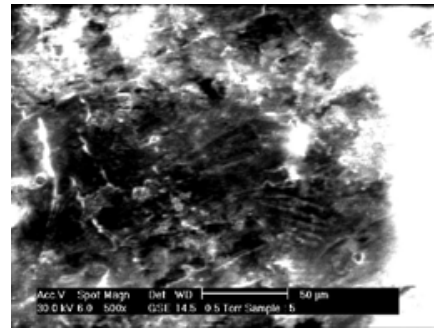

Figure 23. TPU/LDPE/PPCP/ mica

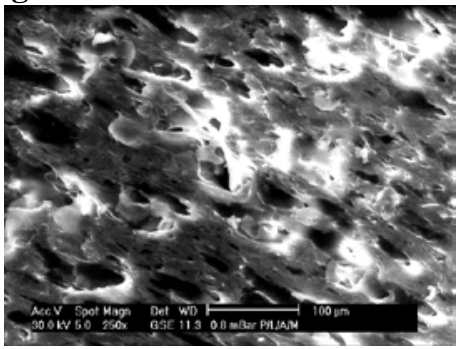

Figure 25. TPU/LDPE/TPU-g-AA/mica

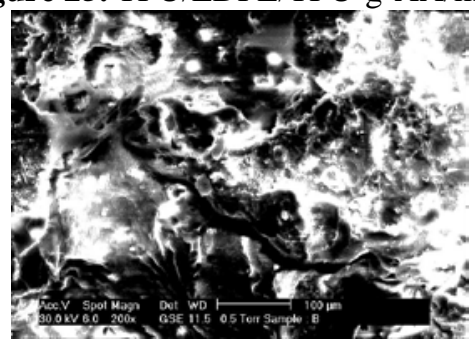

Figure 27. TPU/HDPE/PPCP/ mica

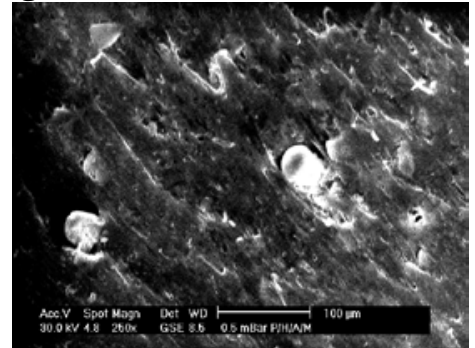

Figure 29. TPU/HDPE/TPU-g-AA/mica

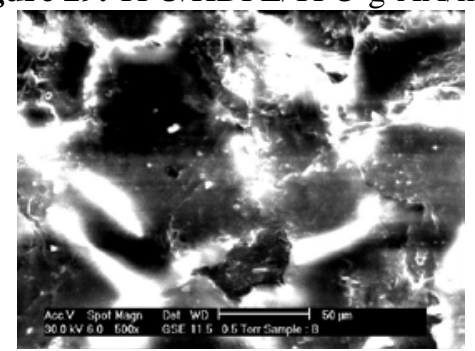

Figure 31. TPU/PP/PPCP/mica 


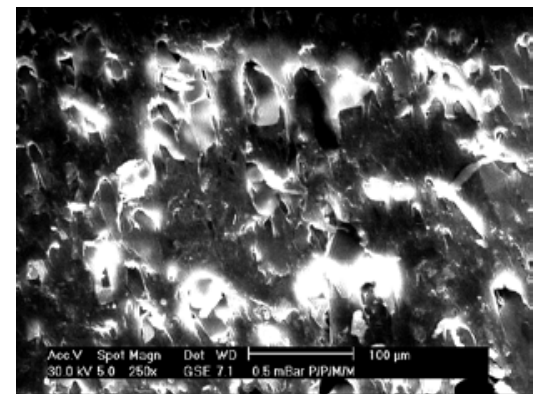

Figure 32. TPU/PP/TPU-g-MA/mica

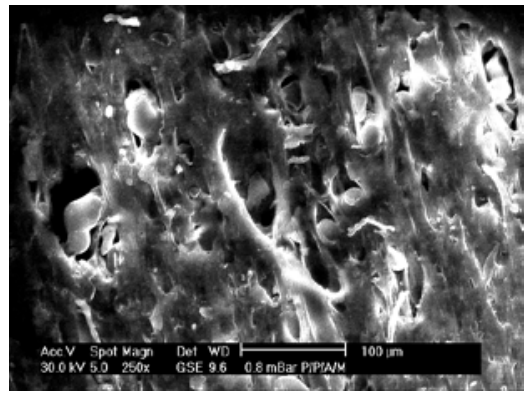

Figure 33. TPU/PP/TPU-g-AA/mica

\section{Conclusion}

Compatibilisers such as polypropylene copolymer (PPCP), TPU-g-MA and TPU-g-AA were found to be good compatibilisers for the TPU/PO blends. Addition of mica as filler into the blends with compatibiliser increased the mechanical properties such as tensile strength, hardness, elongation and decreases the impact strength SEM images show good dispersion of mica filler into the blend matrix.

\section{References}

1. $\quad$ Min Z and Qiang Z, Sci China Chem (Series B), 2008, 51(1), 1-12.

2. Potschke P, Wallheinke K, Fritsche H and Stutz H, J Appl Polym Sci., 1997, 64, 749-762.

3. Arroyo M, Suarez R V, Herrero B and Lopez-Manchado M A, J Mater Chem., 2003, 13, 2915-2921.

4. Hiljanen-Vainio M, Heino M and Seppala J V, Polymer, 1998, 39, 865-872.

5. $\quad$ Kader M A and Bhowmick A K, J Appl Polym Sci., 2003, 90(1), 278-286.

6. González J, Albano C, Candal M V, Hernández M, Ichazo M N, Mayz M A and Martínez A, Study of composites of PP and HDPE with seashells treated with LICA 12. Proceedings of the 8th Polymers for Advanced Technologies International Symposium, Budapest, Hungary, 2005.

7. $\quad$ Maiti S and Mahapatro P, J Appl Polym Sci., 1991, 42, 3101-3110.

8. $\quad$ Premphet K and Horanont P, Polym Plastics Technology Eng., 2001, 40(3), 235-247.

9. Thio Y S, Argon A S, Cohen R E and Weinberg M, Polym., 2002, 43, 3661 -3674.

10. Liu Z H, Kwok K W, Li R K and Choy C L, Polymer, 2002, 43, 2501-2506.

11. González J, Albano C, Ichazo M and Diaz B, Eur Polym J., 2002, 38(12), 2465-2475.

12. Kamble A, Singh V, Thomas M and John N,Chem Sci J., 2011, 1-9.

13. Merlin Thomas, Atul D Kamble and Neetha John, Archives Appl Sci Res., 2012, 4(2), 1191-1202.

14. Unal H, Findik F and Mimaroglu A, J Appl Polym Sci., 2003, 88(7), 1694-1697.

15. Bose S and Mahanwar P A, J Min Mat Char Eng., 2004, 3(1), 23-31.

16. Berlin A, Volfson S, Enikolopian N and Negmatov S, Springer, Berlin, 1986.

17. Sreekanth M S, Bambole V A, Mhaske S T and Mahanwar P A, J Min Mat Char Eng., 2009, 8(3), 271-282. 